\title{
Technology Education and Action Research: Two Complementary Processes to Capacitate Teachers
}

\author{
Tomé Awshar, Mapotse \\ College of Education, Department of Science and Technology, \\ University of South Africa (UNISA), PO Box 392 Pretoria 0003 \\ mapotta@unisa.ac.za
}

\section{Doi:10.5901/mjss.2014.v5n3p338}

\section{Abstract}

Technology Education (TE) across Africa is a key part of improving human resource development. TE offers a multitude of benefits for the continent from improving education and knowledge sharing, to increasing exposure for African innovation with end results of improving the living conditions of the continent's residents. The driving force behind Technology Education is teachers themselves. If teachers are not equipped to teach TE as a process the continent will continue to bear the brunt of unsavoury results unless radical interventions are implemented. It is against this background that Action Research (AR) come handy to emancipate TE teachers of five sampled schools from Mk1 Circuit in Limpopo Province of South Africa. AR was used as a means for radical interventions and it was implemented in South African schools. Some of the notable problems that contribute to the education crisis in South Africa are unqualified or under qualified teachers, large numbers of learners from disadvantaged backgrounds, inadequate delivery of infrastructure, incompetent teaching and poor learner results. The AR cycles and spirals activities of observing, planning, acting and reflecting manage to professionally develop TE teachers from low self-esteem of teaching TE to a remarkable increased TE didactic and pedagogic knowledge levels. The study was underpinned by critical theory and guided by developmental action enquiry paradigm. Reflective questionnaires, nonparticipative observation and interviews were used to collect data. Action Research with technology teachers manages to closes the technology pedagogic content knowledge gap. It should be noted that TE is a late comer in both the national and international school curriculum arena.

Keywords: Critical Theory, Developmental Action Enquiry Paradigm, Technology Pedagogic Content Knowledge

\section{Introduction}

The school subject technology education (called design \& technology and/or named science \& technology in some countries) is a vehicle for inculcating creativity, problem solving and innovation because of its hands-on nature in classroom practices (Mapotse, 2013). Technology education is a late comer within school curriculum both nationally and internationally and therefore it has posed number of challenges different as opposed to other subjects. Amongst the multiple challenges that can be mentioned is the teaching of technology process as the method of teaching TE, ITEA (2000/2003) describes technology as the study of the natural world and is the process by which humans modify nature to meet their needs and wants. It is during the didactic situation that TE teachers need to understand, apply and follow all the steps of the technology process so as to equip their learners with both the design and problem - solving skills. Technology education is the study of the tools, materials, and processes necessary to design and to solve problem (Laufenberg, 2009). An understanding on the TE process by teachers is fundamental to the acquisition of technology literacy (Mapotse, 2001). A gap has been identified that TE teachers are not rooted in the technology process per se hence involving them in action research (AR) to address that lack. Development, emancipation and empowerment of TE teachers through AR become prominent as TE teachers are placed at the forefront to teach learners this relatively new subject.

Some scholars in the technology field have engaged in research targeting variety of aspects of technology education (TE). For instance Letsoalo (2007); Mapotse and Gumbo, (2011); Pudi (2005); Stevens (2006); Techno Moodle (2010); Tholo, Manobe and Lumadi (2011) Williams and Gumbo, (2011). The afore mentioned scholars belonging to both national and global villages have used some common instruments or similar approaches to gather their data and little has been done in using Action Research approach to emancipate technology teachers and conscientise them with learners supervision process of making the technology product. With this study I want to attempt to fill that gap by sharing experiences gained through project supervision. I will be sharing those technology teachers' experiences as a 
critical realist using emancipation paradigm and also underpinning this study through critical theory. If theory could be applied without any interrogation its influence on the study might not be noticed.

\section{Theoretical Framework}

\subsection{The importance of theory in this study}

The philosophical problem that emerges in critical social inquiry is to identify precisely those features of its theories, methods, and norms that are sufficient to underwrite social criticism. A closer examination of paradigmatic works across the whole tradition from Marx's Capital (1871) to the Frankfurt School's Studies in Authority and the Family (1939) and Habermas's Theory of Communicative Action (1982) reveals neither some distinctive form of explanation nor a special methodology that provides the necessary and sufficient conditions for such inquiry. Such a practical account of social inquiry has much in common with pragmatism, old and new (Bohman 1999a, 1999b). As with pragmatism, critical theory came gradually to reject the demand for a scientific or objective basis of criticism grounded in a grand theory. This demand proved hard to square with the demands of social criticism directed to particular audiences at particular times with their own distinct demands and needs for liberation or emancipation.

In most qualitative studies, like this one, theory comes at the beginning and provides a lens that shapes what is looked at and the questions asked especially in a transformative research (Creswell, 2014). Theory in the researcher's thought helps in making research decisions and provide a sense of the world around. Theory is also an explanation that discusses how a phenomenon operates and why it operates as it does and it serves the purpose of making sense out of current knowledge by integrating and summarizing this knowledge, and thus it can be used to guide research by making predictions (Johnson and Christensen, 2004). My choice of critical theory was motivated by my intent to emancipate the technology teachers in terms of overcoming the challenges that they faced in their knowledge and teaching of the subject using the technology process. By reflecting critically on their unfavourable status-quo, technology teachers could be helped to think about how they could free themselves from such unfavourable conditions and take action about it - so to be emancipated. The kind of intervention in such involvement is facilitative rather than instructive, so that those being helped can later be self-reliant and become independent to address their situation. Specifically, the next section explains how critical theory found relevance in this study.

\subsection{The value and application of critical theory in this study}

In the context of this study, critical theory is a social theory oriented towards critiquing and changing technology teachers' circumstances, i.e. their limited technological knowledge and how to teach technology. This study would hopefully create enough awareness in these teachers to be able to pass judgment on their teaching of technology process and to evaluate their knowledge base of technology process with the sole purpose of being emancipated from this situation. Thus, for purposes of this study, critical theory was used to exploit the literature in the field of technology education (Creswell, 1994).

Critical theory indicates that a fundamental dialectical relationship between theory and practice are indivisible (Tooley, 2000), especially in technology. This aligns well with my understanding of technology education, that it is fundamentally a hands-on enterprise. Hands-on in technology must be taken to refer to learning through experiences, that is, through practical engagement in investigating, designing, making, evaluating and communicating ideas and plans (Department of Education [DoE], 2003). Approaching technology education theoretically is unfathomable.

Theory helps in the researcher's thought and in making research decisions and sense of the world around. Theory is also an explanation that discusses how a phenomenon operates and why it operates as it does and it serves the purpose of making sense out of current knowledge by integrating and summarizing this knowledge, and thus it can be used to guide research by making predictions (Johnson \& Christensen, 2004). Critical theory was first defined by Max Horkheimer of the Frankfurt School of sociology in his 1937 essay Traditional and critical theory (Tooley, 2000). The effort to conceptualize critical theory relied on the writings of Karl Marx (Tooley, 2000). Its basic purpose was emancipation and self-determination.

My choice of critical theory was motivated by my intent to emancipate the technology teachers in terms of overcoming the challenges that they faced in their knowledge and teaching of the subject. By reflecting critically on their unfavourable status-quo, technology teachers could be helped to think about how they could free themselves from such unfavourable conditions and take action about it - so to be emancipated. The kind of intervention in such involvement is 
facilitative rather than instructive, so that those being helped can later be self-reliant and become independent to address their situation. Specifically, the next section explains how critical theory found relevance in this study.

\section{Research Problem}

Technology or Design process is the backbone approach for teaching technology education whereas action research is process with emancipation intend to the participants. This paper is an account of the two processes combined within a study; those processes are action research process and technology process. Technology teachers need to expose their learners to all the steps of the technology process and I need to render AR process to these TE teachers. The technology process has the following steps; Investigate, Design, Make, Evaluate and Communicate bearing an acronym IDMEC (Department of Basic Education; Curriculum and Assessment Policy Statement [DBE CAPS], 2011) and action research process integrate the following stages: Observation, Planning, Action and Reflection. Both TE steps and AR stages are not linear and targeting to capacitate the participants from both their pedagogy and didactic of technology. The sections that follow highlight the aim of the study.

\subsection{Aim of the study and research question}

The main aim of this study is to investigate the use of action research initiative to empower, develop and emancipate TE teachers with the technology process. Action Research (AR) study with the senior phase technology education teachers at selected schools of Limpopo Province was motivated by the fact that technology education is a foreign concept to many teachers and a new learning area in school curriculum both nationally and internationally. Thus, a new curriculum known as Curriculum 2005 (reviewed twice already) was developed in which technology was introduced as a new subject.

\subsection{Process within Technology Education}

South Africa (SA) does not have the privilege of having a recorded best practice experience and a history of technology education which teachers can draw on to develop learning programmes. This has a direct impact on teachers because they have to contextualise best practice material from literature for the South African situation.

SA curriculum transformation to introduce technology and thereafter some efforts to improve its quality hails from the fact that SA need to produce engineers, technicians and artisans needed in modern society as well as developing a technological literate population for modern world (DBE CAPS, 2010). For this to be realised, the main players on these are the technology teachers as technology policy (DoE; Revised National Curriculum Statement [RNCS], 2003) reiterate that teaching and learning in technology must be aimed at developing technological literacy so that learners are empowered to cope with the challenges of a technological society. Design or Technological processes as explained by (DBE CAPS, 2011) is a creative human activities of developing technological solutions in order to satisfy human needs and wants (e.g. manufacturing, design, repair, restoration).

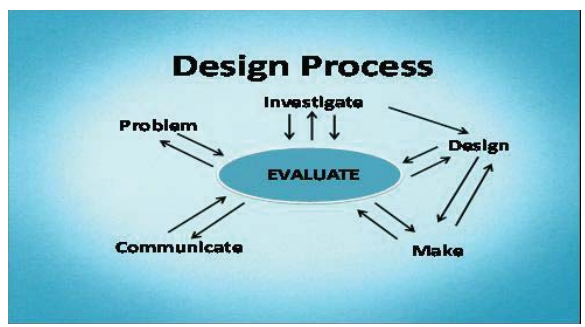

Figure 3.1: The Design Process, Sourced from De Jager (2011).

The design process is non-linear, interactive and each activity in process needs to be evaluative before attempting next activity. The Design Process (Investigating, Designing, Making, Evaluating and Communicating - IDMEC) forms the backbone of the subject and should be used to structure the delivery of all the learning aims. Learners should be exposed to problems, needs or opportunities as a starting point. They should then engage in a systematic process that allows them to develop solutions that solve problems, rectify design issues and satisfy needs (DBE CAPS, 2010). 


\subsection{Action Research Process}

Action research is a process, in which participants examine their own educational practice systematically and carefully, uses the techniques of research (Ferrance, 2000). Action research is a form of collective self-reflective enquiry undertaken by participants in social situation in order to improve rationality and justice of their own social or educational practices, as well as their understanding of these practices and the situation in which these practices are carried out. Groups of participants can be teachers, students, principals, parents and other community members - any group with a shared concern (Kemmis and McTaggart, 1988). In line with this definition, the shared concern is technology education with teachers in Limpopo Province to improve teacher's educational practices of the subject through action research.

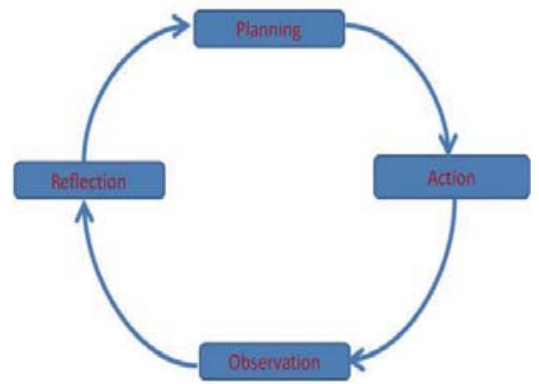

Figure 3.2: Action Research cycle; Sourced from Maseko (2005)

AR is cyclical process of reflecting on practice, taking an action, reflecting, and taking further action. Therefore, the research takes shape while it is being performed. Greater understanding from each cycle points the way to improved actions (Riel, 2010). I tend to display the cycle based on the latter definition of AR. I will abbreviate AR process of planning, action, observation, and reflection as PAOR.

\subsection{How TE and AR complement to capacitate teachers}

IDMEC is a teaching process within Technology Education whereas PAOR is the emancipation process within Action Research. Both processes are not linear as outlined in Table 3.1 below. AR is more cyclical in nature and continues to be spiral after reflective measures are executed by the AR group. TE process can take any form cyclical or linear depending on the facilitator and the nature of the want or need or problem to be technologically being solved. The combination of these two (teaching and emancipation) processes within a structured set-up with teachers of selected schools in Mk1 Circuit of Limpopo Province has yielded capacitated teachers. This is evident in Section 6 under findings and discussion, Sub-Section 6.1 which promulgate vignette of Cycle 1 activities.

These TE teachers can now teach Technology with confidence and every chance of success. AR has complemented TE to capacitate these TE teachers because of its relevance as displayed in Table 3.1.

Table 3.1: The Relevance of AR Process to TE Process

\begin{tabular}{|l|l|}
\hline \multicolumn{1}{|c|}{ Action Research } & \multicolumn{1}{c|}{ Design Process } \\
\hline Identify and verify the problem (investigation) & Identify a technological problem \\
\hline Suggest and plan the solution (consult, methods, etc.) & Investigate the problem (scientific methods) \\
\hline Implement the solution (monitoring methods) & Suggest a practical solution. Make the solution (artefact) \\
\hline $\begin{array}{l}\text { Reflect (workability of solution); may be required to repeat the } \\
\text { loop - next cycle }\end{array}$ & $\begin{array}{l}\text { Evaluate the solution } \\
\text { May be required to repeat the loop - next cycle }\end{array}$ \\
\hline Market the solution & Market the solution \\
\hline NB. Not a linear process & NB. Not a linear process \\
\hline
\end{tabular}

Adapted from Mapotse and Gumbo (2013)

Table 3.1 gives a synopsis of the relevance of AR to TE process. What ensue is the research design and methods of the study. This next section shows the sample and methods used to collect data to make AR process a suitable 
complementary process for TE.

\section{Research Design and Methods}

The sample of five secondary high schools was drawn from Capricorn Region at Mk1 Circuit of Mankweng District. The circuit name has been concealed for ethical reasons. The choice of Mk1 Circuit was prompted by the lack of technology knowledge observed previously by the researcher the time the researcher was lecturing in one university in Limpopo Province. The aim of delineating the scope of the study was to implement some intervention strategies to a manageable sample of technology teachers teaching Grades 8 and 9. Mk1 Circuit was chosen as a cluster sampling strategy. Cluster sampling groups of Grade 8 and 9 technology teachers were randomly selected (Gay, 1987) in terms of their schools, which were more on semi-urban villages.

The following methods were used to collect data from the participants (technology teachers) and those were: non participants' observations, structured interviews and reflective questionnaires. The aim of this study was to establish intervention strategies to empower and emancipate senior phase technology teachers from the challenges that they faced in teaching technology. The intervention strategies were implemented through AR spiral and cyclical processes, the principles for such processes are focused on empowerment, professional development and emancipation of technology teachers. The findings of these processes are discussed in the section that ensues.

\subsection{Research approach}

The collection of data is an important step in deciding what action needs to be taken. Multiple sources of data were used to better understand the scope of what is happening in the technology classroom during technology process. To address the research problem, an inquiry using a qualitative approach was undertaken to ascertain the opinions and experiences of technology teachers regarding technology process steps in constructing learners' project, with a view to further informing the project making agenda and technology process debates. This study was conducted with a small sample of five schools in Limpopo Province, with specific reference to learner projects supervision.

\subsection{Sample of the study}

With the guidance of the circuit manager, the five schools indicated in Table 4.1 (below) from Mk1 Circuit were chosen for their contextual location, convenience in conducting interviews and ease of convening a common venue for contact sessions of AR cycles and activities.

Table 4.1: Sample of selected schools and technology education teachers

\begin{tabular}{|l|c|c|c|c|c|}
\hline Sample Schools & Total & $\begin{array}{c}\text { Non-participative } \\
\text { Observations }\end{array}$ & $\begin{array}{c}\text { Structured } \\
\text { Interviews }\end{array}$ & $\begin{array}{c}\text { Reflective } \\
\text { Questionnaires }\end{array}$ & $\begin{array}{c}\text { School } \\
\text { Milieu }\end{array}$ \\
\hline KMK Sec & 7 & 4 & 5 & 7 & Semi-Urban \\
\hline VMV Sec & 3 & 3 & 3 & 3 & Urban \\
\hline RMR Sec & 3 & 2 & 3 & 3 & Rural \\
\hline BMB Sec & 3 & 2 & 2 & 2 & Rural \\
\hline WHW Sec & 2 & 2 & 15 & 18 & Urban \\
\hline Total & 18 & 13 & & & \\
\hline
\end{tabular}

With pseudonyms assigned to schools for the purposes of anonymity, schools were chosen within a radius of not more than 100 kilometres. The sampling varied in terms of their milieus, i.e., rural, urban and semi-urban, in order to gain biographical information on the need for intervention and degree of challenges they faced in supervising the learners projects. The number of TE teachers and their teaching varied, with some teaching only Grade 8, some only Grade 9. There are many vehicles for the collection of data but in this case I had to select those most appropriate for the issue being researched. Sources used during the main AR study were readily available and data collection was systematically organized and logically structured with the participants well in advance. I organized the data in a way that made it useful to identify trends and themes, collecting it from senior phase technology teachers of Mk1 Circuit through non-participant observations, structured interviews and reflective questionnaires. The next section shows how data was analysed. 


\section{Data Analysis}

Data analysis of Cycle 1 is presented in a narrative form. Tables and figures are used to supplement the analysis information. This process of data analysis focused on understanding the teaching and learning actions and events within the participants' settings and contexts. Data from both interviews and observations were reviewed holistically and important themes noted. The questionnaires had preconceived themes which gave a direction to analyse the data. The themes in the questionnaire were used to guide the analysis even though additional themes developed from the interviews. The findings will be triangulated as displayed in Figure 5.1 below:

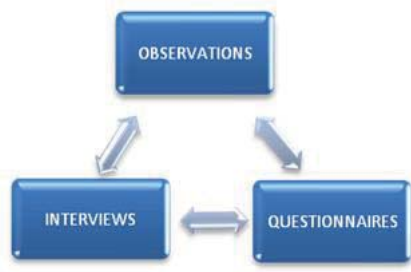

Figure 5.1: Triangulation of findings from the reconnaissance study

Findings from what was observed served as an umbrella to both the interviews and questionnaire. Findings from the interviews sought clarity of the observation and confirmed the themes from the questionnaire. Findings from all the three instruments were integrated since they addressed similar themes; hence they were triangulated (Kerlinger, 1986; Anderson, 1993) since triangulation is one of the strategies that can enhance the validity of a qualitative research.

The use of multiple methods in an investigation is to overcome the weakness or bias of a single method (Denzin, 1988). Triangulation techniques attempted to map out and explain more fully the richness and complexity of teaching technology by studying it from more than one standpoint (Manion and Morrison, 2000). In this study data collected through non-participative observations, semi-structured interviews and qualitative questionnaires were used for triangulation purposes.

\section{Research Findings and Discussion}

\subsection{Vignette of Cycle 1 activities}

This was a proposed schedule of the activities that took place each day in a selected secondary school during Cycle 1. Data was collected each day of the visit at each school from the participants, using only the three instruments during Cycle 1 contact session. Data from both structured interviews and non-participatory observations were reviewed holistically and important themes noted. The reflective questionnaires had preconceived themes which gave a direction to the analysis. The themes in the questionnaire were used as a guide to analysis process of the study. It should be noted that as the study unfold, additional themes emerged from the interviews. Pictures of what I observed within the technology classrooms were taken. Consent forms were signed by both teachers and learners' parents and guardians. This will serve as observation findings in Cycle 1 during Phase 1 as I took photographs of all the classes being taught technology in all the selected schools, and observed that they did not have any technology workshop or laboratory. I also found out that the teachers were using their classes for technology tuition and all other subjects are taught from the same class. The section that follows confirms the gap the teachers still have in applying the design process which is learning outcome 1 (LO1) of TE.

This is how technology teachers still respond to policy related questions after more than a decade of technology establishment. It shows that the country still have a long way to go. I will cite one question from the interviews and participants responses. The question has to do with the design process:-

Question: Can you regard L01 as a method of teaching technology? Support your answer...........

Responses: BMBIP - $03 \rightarrow$ Yes, it emphasise working together, find out from each other that's how they learn from each other.

VMVIP - $01 \rightarrow$ I don't know what it actually covers since there is no policy document that I have been provided with.

RMRIP - $01 \rightarrow$ I don't know.

KMKIP - $06 \rightarrow$ I don't know them by heart, I have to refer

(NB: The first three alphabets is a school code and IP stand for interview participant number) 
With these types of responses, it was clear that TE participants don't have a clue what LO1 entails. LO1 from technology policy document cover the technology process. TE teachers from different schools they don't even know which LO support the process. This was a leading question but the teachers responses suggest that AR should be embarked on with the intended goal of making the difference. I trust that at the end of the AR cycles their responses will be different.

There were eighteen (18) participants in total from the five participating secondary schools, nine male and nine female. Eleven participants had less than six years of technology teaching experience while seven had more than five years. Eleven out of the 18 had no form of technology qualification and seven had some. Thirteen worked in rural areas whereas five worked in urban areas. Ten could plan the technology lessons whereas eight still needed help. Findings from all the three instruments were integrated, triangulated and analysed thematically in the next section.

\subsection{Integrated thematic findings}

\subsubsection{Theme 1: Technology teaching experience}

The reasons for teaching technology by teachers ranged from being coerced into teaching it to the passion for it. For instance, the interviews revealed: "it was just allocated to me"; "it's fun, interesting and compels one to be innovative". Most of technology teachers were generally uncomfortable with the pedagogy of technology as evidenced during both the observations of their teaching and interviews. Some teachers did not have any interest in teaching technology as one contended: "It just came along while I am already teaching and I didn't develops any interest in the subject". The teachers' biographical information confirmed their lack of content knowledge, qualification or experience to a greater extent.

\subsubsection{Theme 2: Technology planning for teaching}

Only seven out of 18 teachers from the questionnaire indicated that they preferred to use both the textbook and a policy document for their lesson planning. During the interviews it seemed that this preference would not materialise as they emphasised: "... if educators were provided with at least a textbook so that we are able to prepare our learning programme"; "I don't think the challenges I meet as stated would have happened if I had relevant and enough textbooks for learners"; "... we need enough textbooks and learner support material".

The technology content matter that the teacher delivers should be obtained from the framework, work schedule, textbooks and the pedagogic content knowledge. This was found not to be the case with the participants as one responded: "We want to be supplied with pacesetters, scheme of work and draft lesson plans". This was confirmed as I requested to view their lesson plans before they presented, but many could not provide it. Only two out of five schools engaged collectively in the development of the technology learning programme.

\section{Conclusion and Recommendations}

TE teachers' were capacitated to implement technology process through action research process. This study was dedicated to outlining how teachers anywhere can teach technology process. TE Teachers has been emancipated to follow the technology process through action research process as confirmed generally by many participants that they can now teach TE with confidence. The cycle programme followed the circuit theme as per their workschedule. This study set out to identify the challenges that the senior phase technology teachers at Mk1 Circuit of Limpopo Province faced regarding their knowledge and teaching of technology design process. A reconnaissance study as part of action research was employed to achieve this goal. I identified the problem as it unfolded. I made certain assumptions surrounding the problem. But since this was an action research study, TE teachers and I embarked on the reconnaissance study to verify our problem and assumptions.

\section{References}

Anderson, G. 1993. Fundamentals of educational research. New York: The Falmer Press.

Bohman, J, 1999a. "Democracy as Inquiry, Inquiry as Democratic: Pragmatism, Social Science, and the Cognitive Division of Labor," American Journal of Political Science, 43: 590-607.

Bohman, J, 1999b. "Theories, Practices, and Pluralism: A Pragmatic Interpretation of Critical Social Science," Philosophy of the Social 
Sciences, 29: 459-480.

Creswell, J.W.1994. Research Design. Qualitative and Quantitative Approaches. Thousand Oaks: Sage.

Creswell, J. W. 2014. Research Design: Qualitative, Quantitative, \& Mixed Methods Approaches (4th ed.). London: SAGE.

Cohen, K. \& Manion, L. 1994. Research Methods in Education (4th ed.). London: Routledge.

Denzin, N.K. 1988. Triangulation. In Keeves, J.P. 1988: Educational research, methodology and measurement. An International Year book. New York: Pergamon Press, pp. 511-513.

De Jager, R. 2011. Latest changes in the Technology Education curriculum in South Africa. Paper delivered at the 25th Annual PATT: CRIPT 8 Conference, "Perspective on Learning in Design \& Technology Education", University of London, London.30 June - 05 July 2011.

Department of Basic Education (DBE). 2010. Curriculum and Assessment Policy Statement (CAPS) Technology Grade 7 - 9 Final Draft [Online]. Accessed on: 15 November 2011. Available at: http://www.education.gov.za/CAPS.asp

Department of Basic Education. 2011. Education in South Africa [Online]. Accessed on: 24 March 2011. Available at: http://www.southafrica.info/about/education/education.htm

Department of Education. 2003. Revised National Curriculum Statement Grades R-9 (Schools): Teacher's guide for developing learning programmes Technology. Pretoria: Government Printers.

De Vos, A.S. (Ed), Strydom, H., Fouche, C.S. \& Delport, L.S.L. 2005. Research at Grass Roots (3rd Edition). Pretoria: Van Schaik.

Ferrance, E. 2000. Action research. Virgin Island: Brown University.

Gay, L.R. 1987. Educational research: Competencies for analysis and application (3rd Ed.). Columbus: Merrill.

ITEA. 2000/2003. Standards for technology literacy: Content for the study of technology. Reston, VA: Author

Johnson, B. \& Christensen, L. 2004. Educational research: Quantitative, qualitative and mixed approaches (2nd Ed.). Boston: Pearson.

Kemmis, S., \& McTaggart, R. 1988. The Action Research Planner. Victoria - Australia: Deakin University Press.

Kerlinger, E.N. 1986. Foundation of behavioural research. New York: Holt, Rinehart \& Winston.

Laufenberg, V (Ed). 2009. About Technology (Online). Accessed on: 15 May 2011. Available at: mhtml: file://B:ITE KIT\AboutTechnology.mht

Letsoalo, M. R. 2007. The need for an instrument to monitor technology process during Technology projects. Polokwane: University of Limpopo (BEd. Hon MST. Ed).

Manion, L. \& Morrison, K. 2000. Research methods in education. London: Routledge

Mapotse, T.A. 2001.Curriculum Evaluation of Technology Education. Pretoria: Technikon Northern Gauteng (MEd Thesis).

Mapotse, T.A. 2013. Emancipation of Technology Education teachers: Educational experiences gained through Action Research. $5^{\text {th }}$ International Conference on Education and New Learning Technologies. 1st $-3^{\text {rd }}$ July 2013, Barcelona, Spain.

Mapotse, T.A. \& Gumbo, M.T. 2011. A reconnaissance study into teaching of Technology in Limpopo Province schools. Southern African Association for Research in Mathematics, Science and Technology Education (SAARMSTE). Proceedings of the

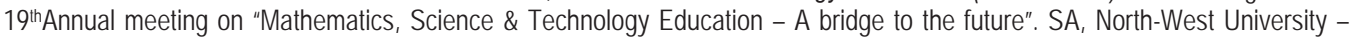
Making Campus, 18 - 21 January.

Mapotse, T.A. \& Gumbo, M.T. 2013. Action Research seminar: How to Conduct and Supervise Action Research studies. 12 September, AJH van der Walt 5 - 17 CEMS Boardroom. Unisa: Pretoria.

Maseko, N.D. 2005. A life skills training workshop for class assistants who work in schools for learners with disabilities. Johannesburg: Rand Afrikaans University (M.Ed. Dissertation).

Tooley, W. R. 2000. Political rationality \& government mechanisms: Maori education policy in the new millennium. MA in Education dissertation. Auckland: University of Auckland.

Pudi, T.I. 2005. Educator roles for Technology Education teacher- educator. Africa Education Review, 34(1): 147-167.

Riel, M. 2010. Understanding Action Research, Centre for Collaborative Action Research. Pepperdine University .Accessed on: 20 October 2010. Available at: http://cadres.pepperdine.edu/ccar/define.html.

Stevens, A. 2006. Technology teacher education in South Africa. International Handbook of Technology Education: Reviewing the past twenty years. M. de Vries \& I. Mottier (ed). Rotterdam: Sense.

Techno Moodle. 2010. The Design Process: Technology, Engineering, Design, and Virtual Learning Environment. Online Classroom, retrieved on 30 May 2012 at http://www.technology education.org/Technomoodle/ thedesignprocess.html

Tholo, J.A.T., Monobe, R.J. \& Lumadi, M.W. 2011. What do boys and girls think about Technology? US-China Education Review, USA, 8(12), 2011.

Tooley, W. R. (2000). Political rationality \& government mechanisms: Maori education policy in the new millennium. MA in Education dissertation. Auckland: University of Auckland.

Williams, P.J. \& Gumbo, M.T. 2011. New Zealand Technology pedagogical content knowledge. In Pupils' Attitude Towards Technology (PATT) 25 and Centre for Research in Primary Technology (CRIPT) 8 on "Perspective on Learning in Design \& Technology Education". Goldsmiths, University of London, 29 June 2011 - 06 July 2011. 